\title{
Antibacterial effects of gum kondagogu reduced/stabilized silver nanoparticles in combination with various antibiotics: a mechanistic approach
}

\author{
Lori Rastogi $\cdot$ Aruna Jyothi Kora $\cdot$ R. B. Sashidhar
}

Received: 3 May 2014/Accepted: 11 August 2014/Published online: 20 August 2014

(C) The Author(s) 2014. This article is published with open access at Springerlink.com

\begin{abstract}
Gum kondagogu reduced/stabilized silver nanoparticles (GK-AgNPs) were evaluated for their increased antibacterial and antibiofilm activities in combination with various antibiotics (ciprofloxacin, streptomycin and gentamicin) against Gram-positive (Staphylococcus aureus 25923, Staphylococcus aureus 49834) and Gram-negative (Escherichia coli 25922, Pseudomonas aeruginosa 27853) bacteria. The micro-broth dilution assay suggested an enhanced antibacterial activity of GK-AgNPs in combination with ciprofloxacin and aminoglycosides (streptomycin and gentamicin) against tested strains. Though the antibacterial activity of GKAgNPs was found to increase significantly in the presence of antibiotics, the \% enhancement was found to depend on both types of antibiotic and bacterial strain. It was also found that GK-AgNPs $(1 \mu \mathrm{g} / \mathrm{mL})$ in combination with various antibiotics at sub-MIC concentrations could inhibit $70 \%$ of the bacterial biofilm formation as compared to respective controls. The enhanced antibacterial activity was due to the increased production of intracellular reactive oxygen species in bacteria when treated with a combination of GK-AgNPs and streptomycin as compared to individual treatment. The increased oxidative stress led to increased membrane damage as assessed by live/dead assay and higher levels of potassium ion release from the cells treated with both silver nanoparticles and
\end{abstract}

\footnotetext{
L. Rastogi · A. J. Kora

National Centre for Compositional Characterisation of Materials (NCCCM), Bhabha Atomic Research Centre, ECIL PO,

Hyderabad 500 062, Telangana, India

R. B. Sashidhar $(\square)$

Department of Biochemistry, University College of Science, Osmania University, Hyderabad 500 007, Telangana, India

e-mail: sashi_rao@yahoo.com
}

streptomycin. The results suggested that the combination of antibiotics with GK-AgNPs has an enhanced antibacterial action. Further, the GK-AgNPs were found to be biocompatible up to a concentration of $2.5 \mu \mathrm{g} / \mathrm{mL}$ as assessed with MTT assay on HeLa cell line. The results suggest that GKAgNPs could potentially be used as in vivo antibacterial agent in combination with antibiotics to overcome the problem of antibiotic resistance.

Keywords Antibacterial · Antibiofilm · Antibiotics . Gum kondagogu $\cdot$ Reactive oxygen species $\cdot$ Silver nanoparticles

\section{Introduction}

Resistance to antibiotics by pathogenic bacteria and fungi has been increasing at a disquieting rate and has become a serious problem, e.g., bacteria like $E$. coli and $S$. typhi have been reported to exhibit resistance to a variety of antibiotics (Wright 2005). Researchers worldwide have been trying to develop new, cost-effective and resistance-free effective antimicrobial agents, due to the prevalence of resistant or even multi-resistant pathogens and the continuing stress on health care costs (Gelatti et al. 2009). There are several examples of silver being widely used as an effective antimicrobial agent since ancient times (Rai et al. 2009). The antimicrobial activity of silver nanoparticles (AgNPs), in particular, is of significant interest because it was found to be effective against even multidrug resistance organisms (Ayala-Núñez and Villegas 2009). The silver nanoparticles are found to have broad spectrum activity and far lower propensity to induce microbial resistance than antibiotics (Inoue et al. 2002). These advantages have led to renaissance of AgNPs-based products like: wound dressings (Maneerung 
et al. 2008), antiseptic creams, water filters (Jain and Pradeep 2005), fabrics (Zhang et al. 2009), etc. However, toxicity issues have led to the limited use of bactericidal silver in nano form and needs to be investigated (Miura and Shinohara 2009). In this context, an alternative and intelligent approach is to effectively use AgNPs in combination with antibiotics so as to achieve desired antimicrobial potential at safe levels of both nano silver and antibiotics. In the recent past, many studies have been carried out to investigate the combinatorial/synergistic effect of AgNPs and antibiotics. It was reported that when amoxicillin and AgNPs are combined, it results in greater bactericidal efficiency on $E$. coli cells than when they were applied separately (Ping et al. 2005). In another study, the antibacterial activities of ampicillin, kanamycin, erythromycin, and chloramphenicol were found to increase in the presence of AgNPs against test strains (Fayaz et al. 2010). Similarly, the antifungal activity of fluconazole was enhanced in the presence of AgNPs against the test fungi (Gajbhiye et al. 2009). The main aim of this study is to investigate the combined effect of natural gum synthesized AgNPs with various antibiotics on both Gram classes of bacteria. In a previous study by our laboratory, we have reported a facile, eco-friendly method for the synthesis of gum kondagogu (Cochlospermum gossypium) reduced/ stabilized silver nanoparticles (GK-AgNPs). The influence of different parameters: gum particle size, concentration of gum, concentration of silver nitrate and reaction time on the synthesis of nanoparticles was studied. At the optimized reaction conditions, it was possible to synthesize nearly monodispersed and size-controlled spherical AgNPs. Using well-diffusion assay, the antibacterial potential of GK-AgNPs was also demonstrated on both Gram classes of bacteria. This study reports the extent of GK-AgNPs synergy with various antibiotics.

\section{Materials and methods}

\section{Materials}

Gum kondagogu, grade-1 (Girijan Co-operative Corporation, Hyderabad, India), Silver nitrate (E. Merck, Mumbai, India), ciprofloxacin hydrochloride, streptomycin sulfate, gentamicin sulfate (Himedia, Mumbai, India), 2,7-dichlorodihydrofluorescein diacetate $\left(\mathrm{H}_{2}\right.$ DCFDA) (Sigma, Bengaluru, India) and LIVE/DEAD BacLight bacterial viability kit L7012 (Molecular probes, Eugene, USA) were used.

Synthesis and characterization of gum kondagogu reduced/stabilized silver nanoparticles (GK-AgNPs)

The GK-AgNPs were prepared as reported earlier by us (Kora et al. 2010). Briefly, dried gum kondagogu tears were powdered in a high-speed mechanical blender (Prestige, Bengaluru, India) and sieved to obtain a mean particle size of $38 \mu \mathrm{m}$. A $1.0 \%(\mathrm{w} / \mathrm{v})$ of homogenous gum stock solution was prepared in ultrapure water by stirring overnight at room temperature. The AgNPs were synthesized by autoclaving the $1 \mathrm{mM}$ silver nitrate solutions containing $0.5 \%$ of gum at $121{ }^{\circ} \mathrm{C}$ and 15 psi for $60 \mathrm{~min}$. The synthesized GK-AgNPs were drop coated on a carbon-coated copper grid and subjected to transmission electron microscopy (TEM) (Philips CM200, The Netherlands) for determination of size and shape. The zeta potential of the nanoparticle solution was measured using a Malvern Zetasizer Nano ZS90 (Worcestershire, UK). The synthesized GK-AgNPs were used without any further purification.

Antibacterial assays

\section{Micro-broth dilution assay}

For determining the minimum inhibitory concentration (MIC) of GK-AgNPs and antibiotics, the micro-broth dilution method (Martinez-Castanon et al. 2008) was used. Staphylococcus aureus ATCC 25923 and Staphylococcus aureus ATCC 49834, and Escherichia coli ATCC 25922 and Pseudomonas aeruginosa ATCC 27853 were used as model test strains for Gram-positive and Gram-negative bacteria, respectively. The assay was performed in a 96-well microtitre plate where the nutrient broth was supplemented with different concentrations of nanoparticles $(1-10 \mu \mathrm{g} / \mathrm{mL})$ and antibiotics: ciprofloxacin $(0.05-0.5 \mu \mathrm{g} / \mathrm{mL})$, streptomycin and gentamicin $(0.1-5 \mu \mathrm{g} / \mathrm{mL})$ followed by inoculation with bacterial cell suspension to obtain $10^{6} \mathrm{CFU} / \mathrm{mL}$. The control wells were maintained without any treatment. The MIC was determined after $48 \mathrm{~h}$ of static incubation at $37{ }^{\circ} \mathrm{C}$ by measuring the absorbance of these culture broths at $600 \mathrm{~nm}$ using a Biotek Synergy ${ }^{\mathrm{TM}} \mathrm{H} 1$ plate reader (Bad Friedrichshall, Germany). To evaluate the synergism between GK-AgNPs and various antibiotics, the sub-MIC concentrations of both GK-AgNPs and antibiotics were added to the wells followed by inoculation with bacterial suspension of $10^{6} \mathrm{CFU} / \mathrm{mL}$. The occurrence and degree of synergism were checked by quantifying the fractional inhibitory concentration (FIC) index as reported earlier (Ghosh et al. 2013). The fractional inhibitory concentration (FIC) index $=$ MIC of GK-AgNPs in combination with antibiotic/MIC of GKAgNPs alone + MIC of antibiotic in combination with GK-AgNPs/MIC of antibiotic alone. If the FIC index $\leq 0.5$, the effect is synergistic, while the value is $0.5<$ FIC $\leq 1.0$ it is additive and a value of FIC $>1.0$ is indifferent. 


\section{Assay for inhibition of biofilm formation}

A modified microtitre plate assay (Uhlich et al. 2006) was performed to see the combinatorial effect of GK-AgNPs and antibiotics on biofilm formation. In brief, sterile, polystyrene microtitre plate wells were inoculated with $200 \mu \mathrm{L}$ of nutrient broth containing $10^{6} \mathrm{CFU} / \mathrm{mL}$ and treated with GK-AgNPs and antibiotics separately and in combination followed by incubation at $37^{\circ} \mathrm{C}$. The negative and positive controls were maintained with untreated and $70 \%$ ethanol $(50 \mu \mathrm{L} / \mathrm{mL})$ treated cells, respectively. After $48 \mathrm{~h}$ of incubation, the medium in the wells was removed and washed with sterile phosphate-buffered saline (PBS) to remove the loosely attached bacteria. The wells were then stained with $200 \mu \mathrm{L}$ of $0.1 \%$ crystal violet for $30 \mathrm{~min}$ at $37^{\circ} \mathrm{C}$. Further, these wells were washed, air dried, the bound stain was solubilized in $200 \mu \mathrm{L}$ of $95 \%$ ethanol and the absorbance was recorded using a Biotek Synergy ${ }^{\mathrm{TM}} \mathrm{H} 1$ micro-plate reader (Bad Friedrichshall, Germany) at $590 \mathrm{~nm}$.

\section{Measurement of intracellular reactive oxygen species (ROS)}

For assessment of intracellular ROS (Choi and Hu 2008), exponentially grown cells were obtained by inoculating the overnight grown bacterial cell suspension $\left(10^{6} \mathrm{CFU} / \mathrm{mL}\right)$ in fresh nutrient broth and incubating at $37^{\circ} \mathrm{C}, 65 \mathrm{rpm}$ for $4 \mathrm{~h}$. Then, the cells were collected by centrifugation $(5,500 \times \mathrm{g}, 10 \mathrm{~min})$, followed by washing and resuspending in PBS. Further, the cells were labeled with $10 \mu \mathrm{M}$ $\mathrm{H}_{2}$ DCFDA $\left(20 \mathrm{~min}, 37^{\circ} \mathrm{C}\right)$ followed by treatment $(1 \mathrm{~h}$, $\left.37{ }^{\circ} \mathrm{C}\right)$ with GK-AgNPs $(2 \mu \mathrm{g} / \mathrm{mL})$ and streptomycin $(0.5 \mu \mathrm{g} / \mathrm{mL})$. The negative and positive controls were maintained with untreated and $70 \%$ ethanol $(50 \mu \mathrm{L} / \mathrm{mL})$ treated cells, respectively. The cells were washed with PBS and the fluorescence intensity was measured using a fluorescence plate reader with excitation and emissions at 490 and $520 \mathrm{~nm}$, respectively.

\section{Measurement of cytoplasmic potassium ion leakage}

The $\mathrm{K}^{+}$leakage analysis (Tiwari et al. 2008) of GKAgNPs and streptomycin treated bacterial cells was done to evaluate the combined effect on bacterial membrane. The cells in exponential grown phase were obtained as detailed in "Measurement of intracellular reactive oxygen species (ROS)". Later, the cells were treated with GKAgNPs $(2 \mu \mathrm{g} / \mathrm{mL})$ and streptomycin $(0.5 \mu \mathrm{g} / \mathrm{mL})$ in PBS followed by incubation at $37{ }^{\circ} \mathrm{C}$ for $4 \mathrm{~h}$. The negative and positive controls were maintained with untreated and $70 \%$ ethanol $(50 \mu \mathrm{L} / \mathrm{mL})$ treated cells, respectively. The cells were centrifuged $(5,500 \times g, 10 \mathrm{~min})$ and the collected supernatants were analyzed for potassium content by a Jobin-Yvon Horiba JY-2000 ICP-OES (Longjumeau, France).

\section{Liveldead assay}

The synergistic effect of GK-AgNPs and streptomycin was also assessed with exponentially grown cells as described in "Measurement of intracellular reactive oxygen species (ROS)", using Live/dead assay (Chamakura et al. 2011). For this, the P. aeruginosa 27853 cells were treated with GK-AgNPs $(2 \mu \mathrm{g} / \mathrm{mL})$ and streptomycin $(0.5 \mu \mathrm{g} / \mathrm{mL})$ for $4 \mathrm{~h}$. Later, the cells were washed, resuspended in PBS and stained with LIVE/DEAD BacLight bacterial viability kit as per manufacturer's instructions. The negative and positive controls were maintained with untreated and $70 \%$ ethanol $(50 \mu \mathrm{L} / \mathrm{mL})$ treated cells, respectively. An aliquot of the stained cells was dropped on the glass slides and observed under LM-52-3001 Lawrence and Mayo epifluorescence microscope (Mumbai, India) under green filter. The digital images of the bacterial cells were captured using a Coolpix P6000 Nikon digital camera (Tokyo, Japan) attached to the microscope.

\section{In vitro cytotoxicity assay}

The HeLa cell cultures were maintained in DMEM with $10 \%$ fetal calf serum. For cell toxicity tests, $2 \times 10^{5}$ cells at the exponential growth phase were seeded in each well of 96-well microtitre plates and incubated in an INC 108 Memmert $\mathrm{CO}_{2}$ incubator (Schwabach, Germany) (5\% $\mathrm{CO}_{2}, 37^{\circ} \mathrm{C}$ ). A series of dilutions containing 1.0, 2.5, 5.0 and $10 \mu \mathrm{g} / \mathrm{mL}$ of GK-AgNPs were dispensed into the wells of microtitre plate. The negative and positive controls were maintained with untreated and doxorubicin $(13 \mu \mathrm{g} / \mathrm{mL})$ treated cells, respectively. The cell viability was measured at $48 \mathrm{~h}$ post-incubation using MTT (3-(4,5-dimethyathiazol-2-yl)-2,5-diphenyl tetrazolium bromide) assay. The assay was based on the measurement of the mitochondrial activity of viable cells by the reduction of tetrazolium salt to form a blue water-insoluble product, formazan (Cao et al. 2010). After $48 \mathrm{~h}$ of incubation, the MTT $(5 \mathrm{mg} / \mathrm{mL})$ was added to the cells and the plates were incubated for additional $4 \mathrm{~h}$. Later, the medium was removed and $200 \mu \mathrm{L}$ of DMSO was added to dissolve the formazan crystals. The absorbance of dissolved formazan was measured at $540 \mathrm{~nm}$ using a Biotek Synergy ${ }^{\mathrm{TM}} \mathrm{H} 1$ plate reader (Bad Friedrichshall, Germany). The absorbance was directly correlated with the number of viable cells and was used to calculate the percentage viability. 

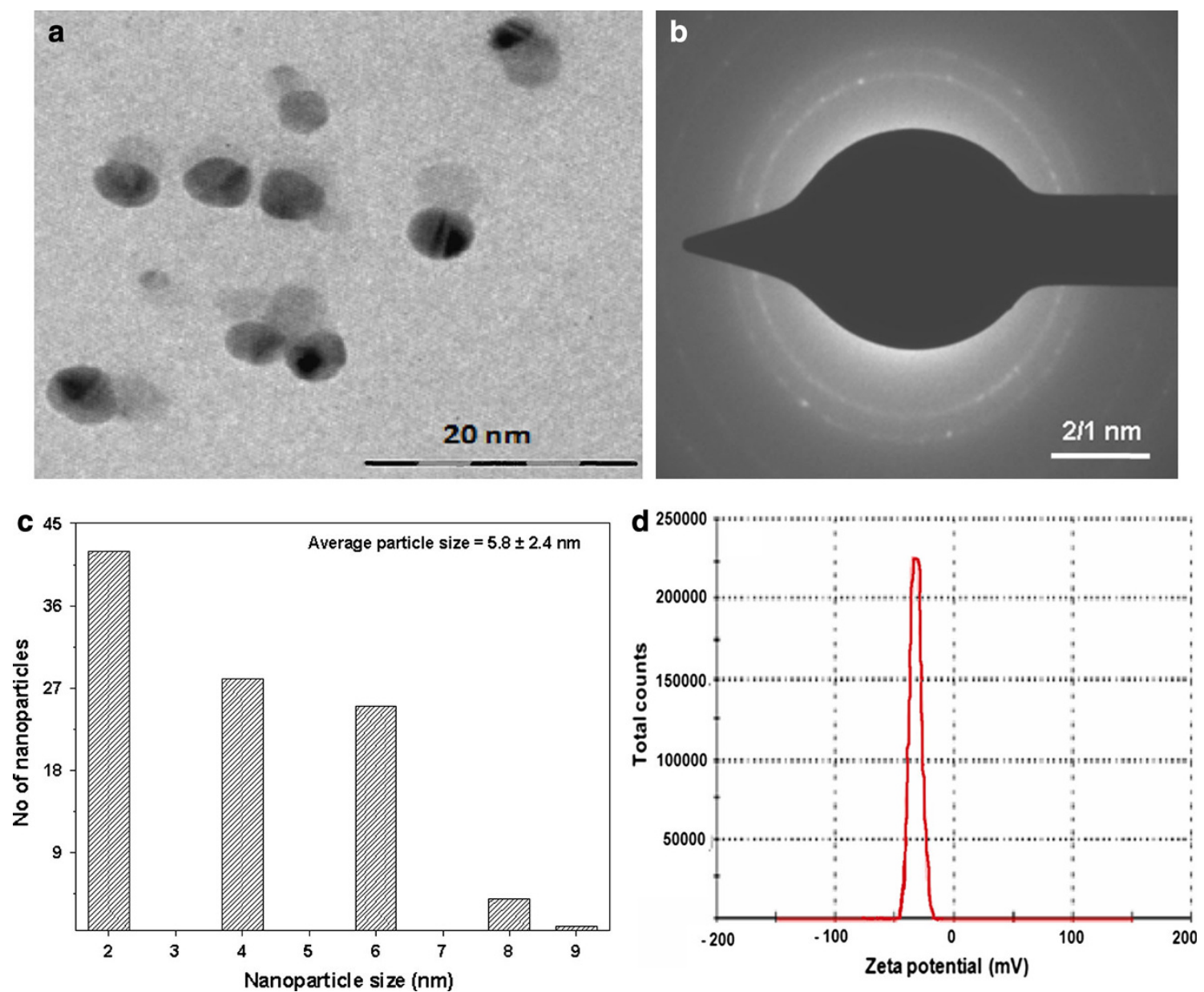

Fig. 1 a TEM micrograph, b SAED pattern, $\mathbf{c}$ histogram, and $\mathbf{d}$ zeta potential distribution of synthesized GK-AgNPs

\section{Statistical analysis}

Three independent experiments were carried out and the results are represented as mean $\pm \mathrm{SD}$. The Student's $t$ test was applied to calculate the statistical significance of the experimental data.

\section{Results and discussion}

\section{Characterization of GK-AgNPs}

The TEM analysis revealed that the AgNPs synthesized with $0.5 \%$ gum and $1 \mathrm{mM}$ silver nitrate by $60 \mathrm{~min}$ of autoclaving; the nanoparticles synthesized were spherical in shape, with an average size of $5.8 \pm 2.4 \mathrm{~nm}$ (Kora et al. 2010). The presence of concentric rings with intermittent bright dots in selected-area electron diffraction (SAED) pattern indicated the crystalline nature of the particles. The zeta potential of the synthesized nanoparticles was found to be $-30.3 \pm 4.1 \mathrm{mV}$, suggesting the stable nature of the GK-AgNPs (Fig. 1).
Micro-broth dilution assay

From the micro-broth dilution assay, the MIC of the AgNPs and antibiotics, streptomycin, gentamicin and ciprofloxacin, were calculated for both the Gram classes of bacteria (Table 1). For E. coli 25922, P. aeruginosa 27853, $S$. aureus 25923 and $S$. aureus 49834 strains, the MIC values of GK-AgNPs were 3.0, 5.0, 5.0 and $5.0 \mu \mathrm{g} / \mathrm{mL}$, respectively. The results suggest that among the test strains, E. coli was found to be more sensitive towards the bactericidal activity of GK-AgNPs. The obtained MIC values were used as reference to calculate the FIC index of antibiotics in combination with GK-AgNPs (Table 1). It was observed that a concentration of $1 \mu \mathrm{g} / \mathrm{mL}$ of AgNPs in combination with either $0.25 \mu \mathrm{g} / \mathrm{mL}$ of streptomycin or $0.5 \mu \mathrm{g} / \mathrm{mL}$ of gentamicin or $0.1 \mu \mathrm{g} / \mathrm{mL}$ of ciprofloxacin was sufficient to inhibit more than $90 \%$ of the bacterial growth in microtitre plates seeded with $10^{6} \mathrm{CFU} / \mathrm{mL}$, as compared to the control. For all the test strains, the FIC index of streptomycin indicated synergistic effect with GKAgNPs. While the FIC values of gentamicin and ciprofloxacin in combination with GK-AgNPs, the effect was 
Table 1 The antibacterial susceptibility of bacterial strains towards GK-AgNPs and antibiotics in terms of MIC and FIC

\begin{tabular}{|c|c|c|c|c|c|c|c|}
\hline \multirow[t]{2}{*}{ Bacterial strain } & \multicolumn{4}{|c|}{ MIC $(\mu \mathrm{g} / \mathrm{mL})$} & \multicolumn{3}{|l|}{ FIC } \\
\hline & GK-AgNPs & Streptomycin & Gentamicin & Ciprofloxacin & Streptomycin & Gentamicin & Ciprofloxacin \\
\hline E. coli 25922 & 3.0 & 1.5 & 2.0 & 0.2 & 0.5 & 0.65 & 0.9 \\
\hline P. aeruginosa 27853 & 5.0 & 1.0 & 1.0 & 0.25 & 0.45 & 0.7 & 0.6 \\
\hline S. aureus 25923 & 5.0 & 2.5 & 2.0 & 0.2 & 0.3 & 0.45 & 0.7 \\
\hline S. aureus 49834 & 5.0 & 1.0 & 1.0 & 0.25 & 0.45 & 0.7 & 0.6 \\
\hline
\end{tabular}

additive. Only with $S$. aureus 25923, the FIC index of gentamicin showed synergism with GK-AgNPs. Thus, the results indicate that the GK-AgNPs have either synergistic or additive effect with various antibiotics and the extent of effect depends both on the type of antibiotic and bacterial strain tested. These results are in concurrence with earlier studies carried out against spore-forming bacteria with combination of cinnamaldehyde with silver nanoparticles, in which at least an additive or near synergistic effect was observed (Ghosh et al. 2013). It is evident that among the antibiotics, streptomycin demonstrated highest activity against both the Gram classes of bacteria with AgNPs, in terms of synergism. Such an enhancement in antibacterial activity was earlier reported with streptomycin-loaded protein-capped gold nanoparticles (Rastogi et al. 2012) and collective activity of streptomycin and PVP-capped silver nanoparticles (Kora and Rastogi 2013).

The observations made in the present study have been compared with contemporary literature in relation to the enhanced antibacterial action of silver nanoparticles in combination with various antimicrobial agents. In an earlier synergistic antibacterial study with silver nanoparticles of 5-40 nm size, MIC values of 30 and $80 \mu \mathrm{g} / \mathrm{mL}$ were reported for $E$. coli and $S$. aureus strains, respectively. With disk diffusion assay against test strains, the antibacterial activities of ampicillin, kanamycin, erythromycin and chloramphenicol were increased in the presence of AgNPs (Fayaz et al. 2010). With the same test strains, the combined antibacterial activity of $16 \mathrm{~nm}$ sized PVP capped AgNPs with streptomycin, ampicillin and tetracycline was enhanced (Kora and Rastogi 2013). The combined efficacy of ciprofloxacin and gentamicin antibiotics with silver nanoparticles of 5-30 $\mathrm{nm}$ size was reported to be augmented against multidrug-resistant $E$. coli, $P$. aeruginosa and $S$. aureus strains (Naqvi et al. 2013). In another study using silver nanoparticles of $32.5 \mathrm{~nm}$, the antifungal activity of fluconazole was enhanced in the presence of AgNPs against the test fungi (Fayaz et al. 2010). It is pertinent to note that all these studies were carried out with solid agar assays in contrast to broth-based assays used in the present study. In an earlier broth-based study carried out with AgNPs of $20 \mathrm{~nm}$ size, an MIC value of $40 \mu \mathrm{g} / \mathrm{mL}$

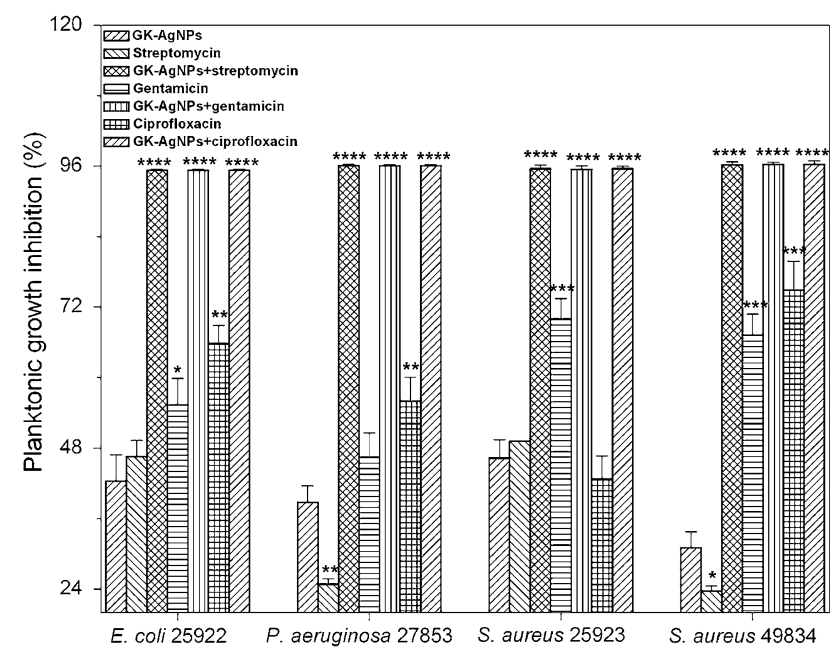

Fig. 2 The \% inhibition in planktonic growth of different bacterial strains treated with GK-AgNPs and antibiotics individually and in combination. Values are mean $\pm \mathrm{SD}$ for $n=3$; $* p<0.05$, $* * p<0.005, * * * p<0.001$ and $* * * * p<0.0001$ compared to GKAgNPs treated cells

was reported and the combination of amoxicillin and AgNPs resulted in greater bactericidal efficiency against $E$. coli (Ping et al. 2005). The activity of $25-40 \mathrm{~nm}$ sized silver nanoparticles against $E$. coli, $P$. aeruginosa and $S$. aureus strains was greatly enhanced in micro-broth dilution method, when utilized in the presence of cinnamaldehyde, a food grade antimicrobial agent. For the respective strains, the reported MIC values of AgNPs were 0.6, 6.1 and $3.0 \mu \mathrm{g} / \mathrm{mL}$. With same ATCC strains used in the present study; E. coli 25922, P. aeruginosa 27853 and S. aureus 25923, synergistic or near synergistic antibacterial activity of ampicillin, chloramphenicol and kanamycin were demonstrated with silver nanoparticles of $3 \mathrm{~nm}$ size and the reported MIC values AgNPs were 2.0, 0.5 and $0.5 \mu \mathrm{g} / \mathrm{mL}$, respectively (Hwang et al. 2012).

The various degrees of planktonic growth inhibition induced by GK-AgNPs in combination with various antibiotics against used test strains are shown in Fig. 2. For E. coli 25922 and S. aureus 49834 strains, gentamicin and ciprofloxacin individually caused higher biofilm inhibition compared to the KG-AgNPs. Also with $P$. aeruginosa 


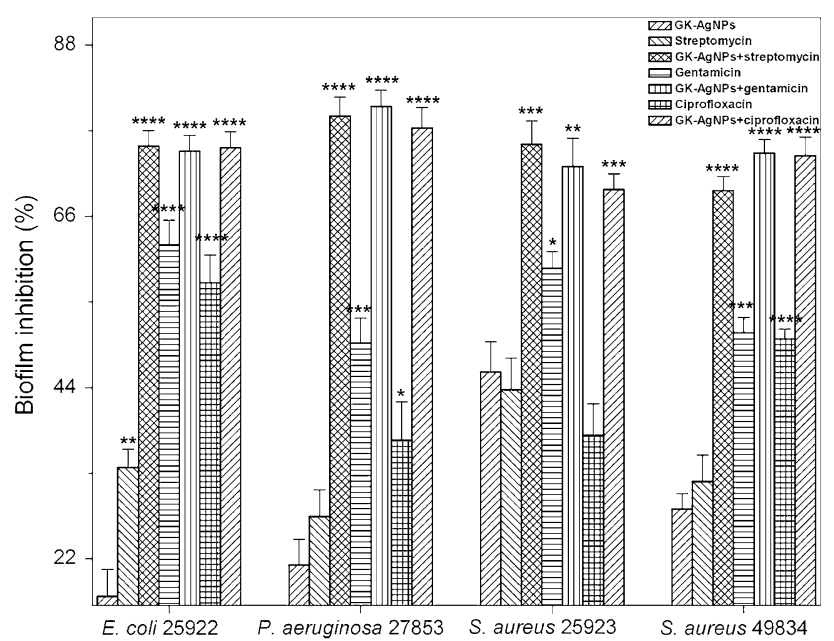

Fig. 3 The \% inhibition in biofilm formation of different bacterial strains treated with GK-AgNPs and antibiotics individually and in combination. Values are mean $\pm \mathrm{SD}$ for $n=3 ; * p<0.05$, $* * p<0.005, * * * p<0.001$ and $* * * * p<0.0001$ compared to GKAgNPs treated cells

27853 and S. aureus 25923, ciprofloxacin and gentamicin showed higher inhibition of biofilm formation than KGAgNPs, respectively. Nevertheless, the combination of KG-AgNPs with all the antibiotics resulted in 95.2, 96.0, 95.5 and $96.2 \%$ growth inhibition for E. coli 25922, $P$. aeruginosa 27853, S. aureus 25923 and S. aureus 49834, respectively.

\section{Inhibition of biofilm formation}

The results obtained from the micro-broth dilution assay were again confirmed from the biofilm inhibition assay against tested bacterial strains (Fig. 3). As shown in Fig. 2 that $1 \mu \mathrm{g} / \mathrm{mL}$ of AgNPs in combination with either $0.25 \mu \mathrm{g} / \mathrm{mL}$ of streptomycin or $0.5 \mu \mathrm{g} / \mathrm{mL}$ of gentamicin or $0.1 \mu \mathrm{g} / \mathrm{mL}$ of ciprofloxacin was able to significantly inhibit the biofilm formation in both Gram classes of bacteria. For Gram-negative E. coli, all the antibiotics individually caused higher biofilm inhibition compared to the KG-AgNPs. Also with P. aeruginosa 27853 and S. aureus 49834, gentamicin and ciprofloxacin showed higher inhibition of biofilm formation than KG-AgNPs. However, the combined activity of both the agents impeded $\geq 70 \%$ of biofilm formation.

\section{Generation of intracellular ROS}

The antibacterial activity of AgNPs was found to be related to the formation of free radicals. Furthermore, the free radicals generated by the AgNPs induce bacterial cell membrane damage which is considered to be the main cause of cell death. Though the ROS can exist naturally in

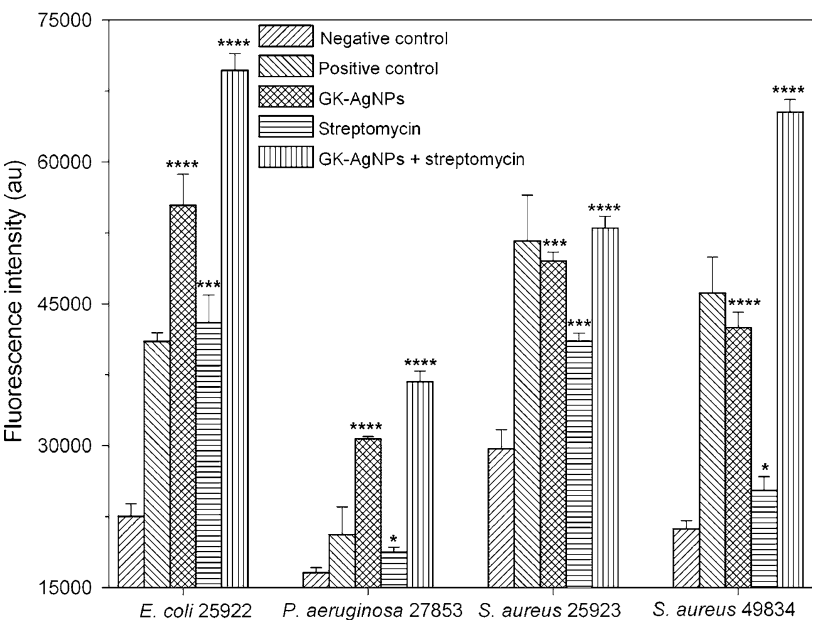

Fig. 4 A bar graph showing the fluorescence intensities of various bacterial strains due to intracellular ROS generation after exposure with GK-AgNPs and streptomycin individually and in combination. Negative and positive controls denote untreated and $70 \%$ ethanoltreated bacterial cell suspensions. Values are mean \pm SD for $n=3$; $* p<0.05, * * * p<0.001$ and $* * * * p<0.0001$ compared to negative control

intracellular and extracellular locations, under certain conditions, high levels of ROS can cause oxidative stress in cells and lead to redox imbalance (Choi and Hu 2008). In this study, $\mathrm{H}_{2}$ DCFDA was used to measure the intracellular ROS levels after various treatments (Fig. 4). For the cells treated with GK-AgNPs and streptomycin individually, a significant increase in ROS levels was observed as compared to the untreated cells. However, the cells treated with the combination of both GK-AgNPs and streptomycin showed even higher levels of ROS. The treatment of $S$. aureus 49834 cells individually with GK-AgNPs and streptomycin led to 2.0 and 1.1 fold increase in ROS generation, while a combined treatment with both the agents led to 3.0 fold increase in intracellular ROS levels. Similar pattern of ROS levels was observed for all other bacterial strains tested, though the fold increase in levels depended on the type of bacterial strain.

\section{Cytoplasmic potassium ion leakage}

The bacterial membrane damage was further confirmed by quantifying the leakage of cytoplasmic potassium content. The leakage of cytoplasmic $\mathrm{K}^{+}$has been correlated to the extent of membrane damage by several researchers (Tiwari et al. 2008). A significant increase in the levels of $\mathrm{K}^{+}$was found in cells treated with GK-AgNPs for all the bacterial strains, when compared to negative and positive controls. But, the cells treated with streptomycin alone did not exhibit any considerable increase in the $\mathrm{K}^{+}$levels. When the cells were exposed to both the GK-AgNPs and streptomycin, the $\mathrm{K}^{+}$levels were higher than the cells treated 


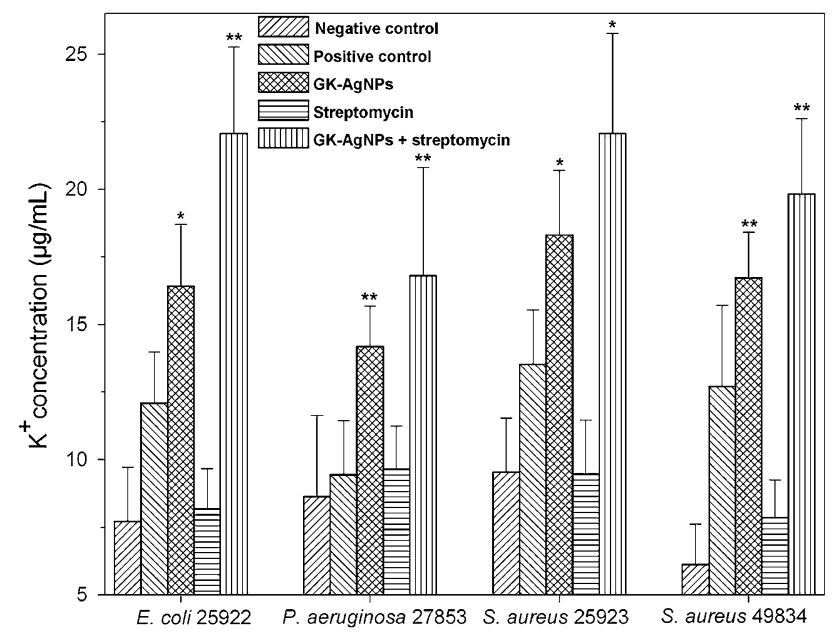

Fig. 5 The intracellular $\mathrm{K}^{+}$leakage of test bacterial strains after treatment with GK-AgNPs and streptomycin individually and in combination. Negative and positive controls denote untreated and $70 \%$ ethanol-treated bacterial cell suspensions. Values are mean \pm SD for $n=3$; *p $<0.05$ and $* * p<0.005$ compared to negative control with GK-AgNPs alone (Fig. 5). Though streptomycin alone was not able to cause much leakage of intracellular $\mathrm{K}^{+}$, still an increase in $\mathrm{K}^{+}$leakage was observed when combined with AgNPs. The increased oxidative stress can cause damage not only to cell membrane, but also to proteins, DNA and components of respiratory system which in turn are responsible for augmented effect offered by GKAgNPs and streptomycin combination.

\section{Fluorescence microscopy}

The damage to bacterial membrane was also estimated with Live/dead BacLight kit by differentiating the live and dead bacteria under fluorescence microscope. The viable cells with intact membrane were visualized by their green fluorescence under blue light and the dead cells with damaged membranes by their red fluorescence under green light. The fluorescence micrographs of $P$. aeruginosa 27853 control cells showed numerous intact green colored viable cells. Whereas, the cells treated with ethanol, GK-
Fig. 6 The fluorescence micrographs of $P$. aeruginosa cells, a Control, b treated with streptomycin, $\mathbf{c}$ treated with GK-AgNPs and d treated with GK-AgNPs + streptomycin
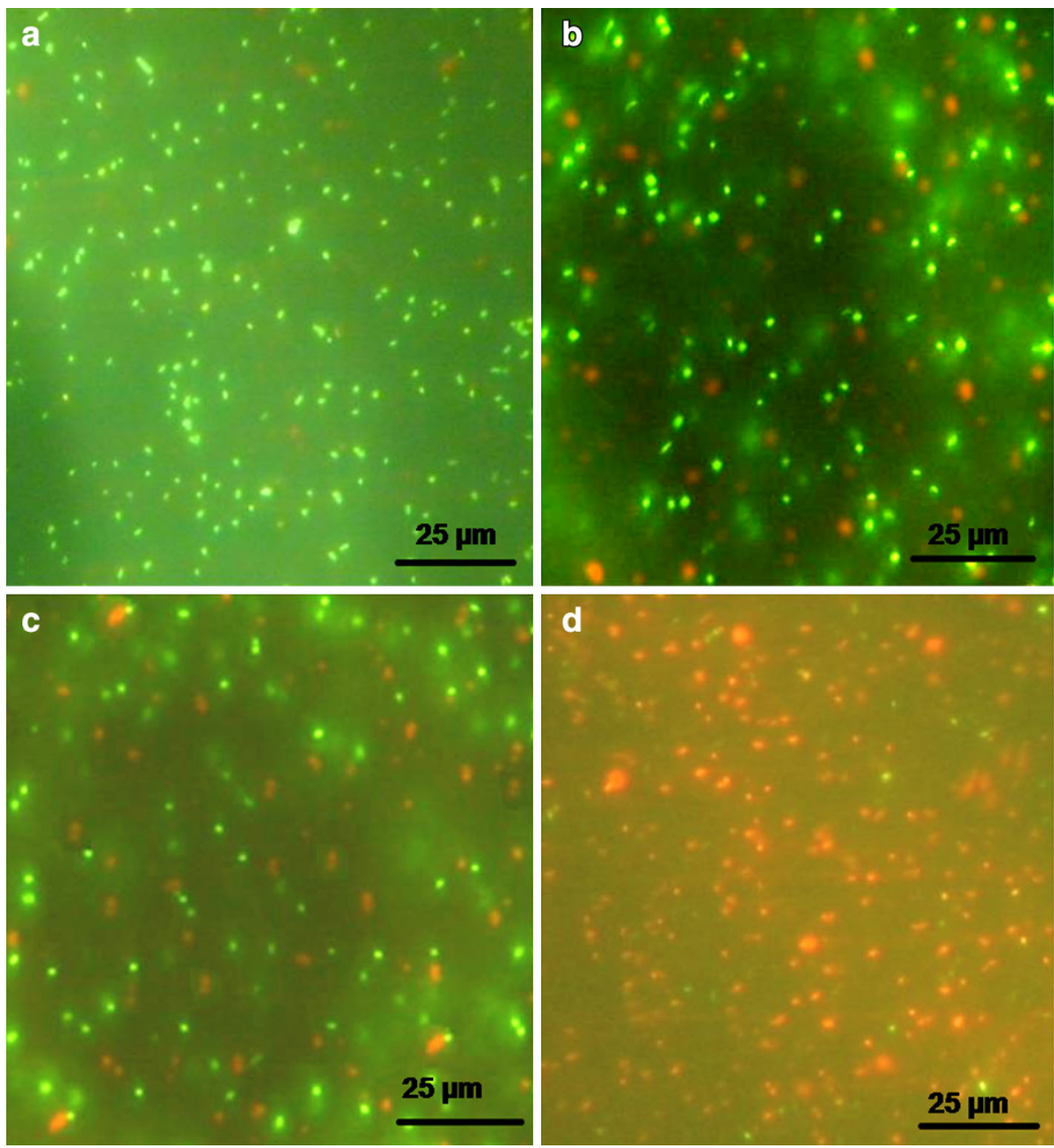


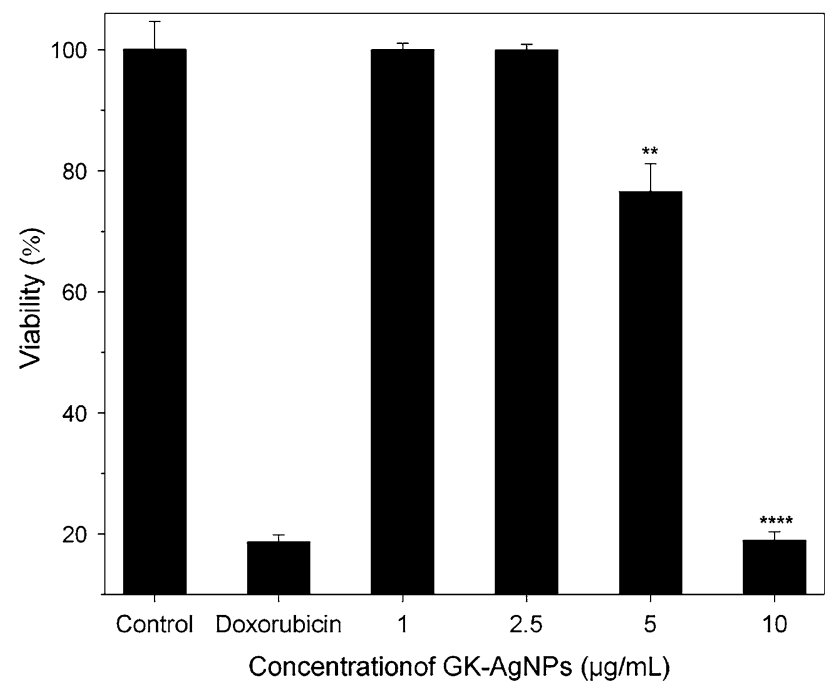

Fig. 7 The $\%$ viability of HeLa cells treated with increasing concentration of GK-AgNPs $(1-10 \mu \mathrm{g} / \mathrm{mL})$. Untreated and doxorubicin-treated cells were used as negative and positive controls. Values are mean $\pm \mathrm{SD}$ for $n=3$; **p $<0.005$ and ****p $<0.0001 \mathrm{com}-$ pared to negative control

Ag-NPs and streptomycin showed several intense red colored cells. Further, the cells treated with both GK-AgNPs and streptomycin showed a higher population of red cells (Fig. 6). Thus, the fluorescence microscopic analyses demonstrate a higher cell wall and membrane damage, leading to an increase in cell death in bacteria treated with the combination of GK-Ag-NPs and streptomycin.

\section{Evaluation of in vitro cytotoxicity}

The biocompatibility of the silver nanoparticles was evaluated with HeLa cell line for their use in combination with antibiotics. HeLa cells were selected for cytotoxic studies as they are durable, prolific and can be grown very easily in $5 \%$ serum-supplemented standard DMEM medium with no specific growth component requirement. The $\%$ viability of the cells was plotted against nanoparticles concentration at $48 \mathrm{~h}$. The concentrations of nanoparticles up to $2.5 \mu \mathrm{g} \mathrm{mL}^{-1}$ were not cytotoxic. Beyond the concentration of $2.5 \mu \mathrm{g} / \mathrm{mL}$, they were cytotoxic and the cell viability was reduced to $76.5 \%$ and $18.9 \%$ at $5 \mu \mathrm{g} / \mathrm{mL}$ and $10 \mu \mathrm{g} /$ $\mathrm{mL}$, respectively (Fig. 7). In the case of doxorubicin-treated positive control, the viability was reduced to $18.6 \%$. Thus, the data suggest that non-cytotoxic concentrations of antibacterial GK-AgNPs can be used for biomedical and therapeutic purposes (Ayala-Núñez and Villegas 2009).

\section{Conclusions}

In this study, we have demonstrated the synergistic and additive antibacterial effect of GK-AgNPs with aminoglycosidic and ciprofloxacin antibiotics, respectively, against both Gram classes of bacteria. It was found that the extent of enhancement was dependent on both bacterial strain and type of antibiotic in combination. The results may pave the way for the combined use of AgNPs and antibiotics towards decreasing the antibiotic resistance currently observed for certain bacteria. Research over last several years has confirmed that nanoscale materials can lead to unpredicted and abnormal toxicity and hence the dose is very crucial. Taking care of this point, by standardizing the concentration of antibiotics, we have shown more than $90 \%$ of bacterial growth inhibition at non-cytotoxic levels of GK-AgNPs $(1 \mu \mathrm{g} / \mathrm{mL})$. Thus, in combination with antibiotics, the antibacterial efficiency and safety of GK-AgNPs were established for potential in vivo applications.

Acknowledgments The authors would like to thank Dr. D. Karunasagar, Head, EACS and Dr. Sunil Jai Kumar, Head, NCCCM/BARC for their constant support and encouragement throughout the work.

Open Access This article is distributed under the terms of the Creative Commons Attribution License which permits any use, distribution, and reproduction in any medium, provided the original author(s) and the source are credited.

\section{References}

Ayala-Núñez NV, Villegas HHL et al (2009) Silver nanoparticles toxicity and bactericidal effect against methicillin-resistant Staphylococcus aureus: nanoscale does matter. Nanobiotechnology 5:2-9

Cao X, Cheng C, Ma Y, Zhao C (2010) Preparation of silver nanoparticles with antimicrobial activities and the researches of their biocompatibilities. J Mater Sci 21:2861-2868

Chamakura K, Perez-Ballestero R, Luo Z, Bashir S, Liu J (2011) Comparison of bactericidal activities of silver nanoparticles with common chemical disinfectants. Colloid Surf B 84:88-96

Choi O, Hu Z (2008) Size dependent and reactive oxygen species related nanosilver toxicity to nitrifying bacteria. Environ Sci Technol 42:4583-4588

Fayaz AM, Balaji K, Girilal M, Yadav R, Kalaichelvan PT, Venketesan R (2010) Biogenic synthesis of silver nanoparticles and their synergistic effect with antibiotics: a study against grampositive and gram-negative bacteria. Nanomedicine 6:103-109

Gajbhiye M, Kesharwani J, Ingle A, Gade A, Rai M (2009) Fungusmediated synthesis of silver nanoparticles and their activity against pathogenic fungi in combination with fluconazole. Nanomed Nanotechnol Biol Med 5:382-386

Gelatti LC, Bonamigo RR, Becker AP, dAzevedo PA (2009) Methicillin-resistant Staphylococcus aureus: emerging community dissemination. An Bra Dermatol 84:501-506

Ghosh IN, Patil SD, Sharma TK, Srivastava SK, Pathania R, Navani NK (2013) Synergistic action of cinnamaldehyde with silver nanoparticles against spore-forming bacteria: a case for judicious use of silver nanoparticles for antibacterial applications. Int $\mathbf{J}$ Nanomed 8:4721-4731

Hwang I-S, Hwang JH, Choi H, Kim K-J, Lee DG (2012) Synergistic effects between silver nanoparticles and antibiotics and the mechanisms involved. J Med Microbiol 61:1719-1726 
Inoue $\mathrm{Y}$ et al (2002) Bactericidal activity of Ag-zeolite mediated by reactive oxygen species under aerated conditions. J Inorg Biochem 92:37-42

Jain P, Pradeep T (2005) Potential of silver nanoparticle-coated polyurethane foam as an antibacterial water filter. Biotechnol Bioeng 90:59-63

Kora AJ, Rastogi L (2013) Enhancement of antibacterial activity of capped silver nanoparticles in combination with antibiotics, on model Gram-negative and Gram-positive bacteria. Bioinorg Chem Appl 2013:1-7

Kora AJ, Sashidhar RB, Arunachalam J (2010) Gum kondagogu (Cochlospermum gossypium): a template for the green synthesis and stabilization of silver nanoparticles with antibacterial application. Carbohydr Polym 82:670-679

Maneerung T, Tokura S, Rujiravanit R (2008) Impregnation of silver nanoparticles into bacterial cellulose for antimicrobial wound dressing. Carbohydr Polym 72:43-51

Martinez-Castanon GA, Nino-Martinez N, Martinez-Gutierrez F, Martinez-Mendoza JR, Ruiz F (2008) Synthesis and antibacterial activity of silver nanoparticles with different sizes. J Nanopart Res 10:1343-1348

Miura N, Shinohara Y (2009) Cytotoxic effect and apoptosis induction by silver nanoparticles in HeLa cells. Biochem biophyl res comm 390:733-737
Naqvi SZH, Kiran U, Ali MI, Jamal A, Hameed A, Ahmed S, Ali N (2013) Combined efficacy of biologically synthesized silver nanoparticles and different antibiotics against multidrug-resistant bacteria. Int J Nanomed 8:3187-3195

Ping L, Juan L, Changzhu W, Qingsheng W, Jian L (2005) Synergistic antibacterial effects of $\beta$-lactam antibiotic combined with silver nanoparticles. Nanotechnol 16:1912-1917

Rai M, Yadav A, Gade A (2009) Silver nanoparticles as a new generation of antimicrobials. Biotechnol Adv 27:76-83

Rastogi L, Kora AJ, Arunachalam J (2012) Highly stable, protein capped gold nanoparticles as effective drug delivery vehicles for amino-glycosidic antibiotics. Mater Sci Eng C 32:1571-1577

Tiwari DK, Behari J, Sen P (2008) Time and dose-dependent antimicrobial potential of $\mathrm{Ag}$ nanoparticles synthesized by topdown approach. Curr Sci 95:647-655

Uhlich GA, Cooke PH, Solomon EB (2006) Analyses of the red-dryrough phenotype of an Escherichia coli O157:H7 strain and its role in biofilm formation and resistance to antibacterial agents. Appl Environ Microbiol 72:2564-2572

Wright GD (2005) Bacterial resistance to antibiotics: enzymatic degradation and modification. Adv Drug Deliv Rev 57:1451-1470

Zhang F, Wu X, Chen Y, Lin H (2009) Application of silver nanoparticles to cotton fabric as an antibacterial textile finish. Fiber Polym 10:496-501 